\title{
Modelo analítico de suporte à configuração e integração da cadeia de suprimentos
}

\author{
Analytical model of support for setting \\ up and integratiing a supply chain
}

\author{
Josenildo Brito de Oliveira ${ }^{1}$ \\ Maria Silene Alexandre Leite ${ }^{2}$
}

\begin{abstract}
Resumo: O objetivo deste artigo é propor um modelo analítico de suporte à configuração e integração da cadeia de suprimentos como base ao desenvolvimento e/ou melhoria de projetos SCM. Os aspectos metodológicos basearam-se em uma revisão de literatura sobre temas relacionados à gestão da cadeia de suprimentos e cadeias de valor. A natureza da pesquisa empregada nesse artigo é básica, uma vez que se produziu um instrumento teórico sem aplicação prática. Foi estabelecida uma estrutura conceitual subsidiada por uma pesquisa bibliográfica, exploratória e descritiva, promovendo os fundamentos necessários ao desenvolvimento do modelo proposto. A abordagem dada ao artigo é qualitativa, cujos resultados teóricos produzidos representaram a proposição de um modelo analítico desenvolvido para configurar adequadamente a cadeia de suprimentos, integrando várias perspectivas necessárias a uma melhor contextualização das interações entre os elos e membros do arranjo. Portanto, esse artigo concebeu um instrumento para auxiliar na melhoria ou desenvolvimento de projetos de gestão da cadeia de suprimentos.
\end{abstract}

Palavras-chave: Modelo analítico. Configuração. Cadeia de suprimentos. Projetos SCM.

\begin{abstract}
The objective of this article is to propose an analytical model of support to the configuration and integration of the supply chain as the basis for the development and/or improvement of SCM projects. The methodological aspects were based on a review of the literature on issues related to supply chain management and value chains. The nature of the research used in this article is basic since it produced a theoretical instrument without practical application. A conceptual structure was built supported by an exploratory and descriptive literature review providing the foundation for the development of the proposed model. The approach of this article is qualitative. The theoretical results obtained represent the proposition of an analytical model developed to properly set up the supply chain integrating various perspectives for a better contextualization of the interactions between the links and members of arrangement. Thus, this article proposes a tool to assist in the development or improvement of projects for supply chain management.
\end{abstract}

Keywords: Analytical Model. Set up. Supply Chain. Projects SCM.

\section{Introdução}

A abertura dos mercados trouxe um cenário de intensa concorrência global. Empresas passaram a competir não mais localmente, mas rompendo fronteiras comerciais e territoriais. Hoje a competitividade já alcança grandes cadeias de suprimentos. A disputa pelo share se aloja nas perspectivas da competência e do nível de disputa da cadeia de suprimentos em oferecer um nível melhor de serviço sem que o consumidor pague mais por isso. Alguns fatores contribuíram para esse cenário: melhoria dos processos de produção, em particular nos ambientes avançados de manufatura (TUBINO et al., 2007); da visão focada no produto ao atendimento responsivo de requisitos dos clientes (CHRISTOPHER, 2007); uso da tecnologia de informação no compartilhamento de processos (CHOPRA; MEINDL, 2003; CARR; KAYNAK, 2007; SKIPPER et al., 2008); integração intra e interempresarial (STANK et al., 2001, SAMARANAYAKE, 2005; DONK et al., 2008); complexidade na gestão dos arranjos (LAMBERT et al., 1998; MENTZER et al., 2001, MORGAN, 2007), entre outros.

Visando superar os desafios provenientes da acirrada competição e acompanhar a evolução no nível de exigência dos consumidores, as empresas passaram

\footnotetext{
' Programa de Pós-Graduação em Engenharia de Produção - PPGEP, Universidade Federal da Paraíba - UFPB, Rua Osvaldo Cruz, 847, Centenário, Campina Grande - PB, E-mail: josenildo_brito@yahoo.com.br

2 Programa de Pós-Graduação em Engenharia de Produção - PPGEP, Universidade Federal da Paraíba - UFPB, Campus Universitário, Centro de Tecnologia, Cidade Universitária, João Pessoa - PB, E-mail: leite@ ct.ufpb.br
}

Recebido em 12/9/2008 — Aceito em 18/5/2010

Suporte financeiro: $\mathrm{CNPq}$. 
a formar arranjos para obter vantagens competitivas que dificilmente conseguiriam se atuassem de maneira isolada das outras empresas. A cadeia de suprimentos representa um formato empresarial que se insere num contexto de grande complexidade, dado o grande número de interações trocadas entre os membros da cadeia, tornando a gestão mais difícil (MORGAN, 2007). Uma cadeia de suprimentos, para Mentzer et al. (2001), é um conjunto de três ou mais entidades diretamente envolvidas com o fluxo, a montante e a jusante, de produtos, serviços, finanças, e/ou informações da fonte ao consumidor. As dificuldades na gestão dessas relações podem se evidenciadas por diversos autores (MOBERG et al., 2004; CHOY et al., 2007; FORSLUND, 2007; TÖYLI et al., 2008). De acordo com Lambert, Cooper e Pagh (1998), a cadeia de suprimentos representa todas as organizações com as quais a empresa líder de um arranjo interage direta ou indiretamente através de seus fornecedores e clientes.

O conceito de logística integrada criado para integrar operações logísticas no âmbito interno da empresa estimulou o surgimento do conceito SCM (Supply Chain Management) ou gestão da cadeia de suprimentos. Pela análise da literatura não é possível identificar com certa precisão a origem do termo (COOPER et al., 1997; LAMBERT et al., 1998; PIRES, 2004). Observou-se, entretanto, que os processos de negócios entre os participantes da cadeia de suprimentos necessitavam de integração.

Essa integração foi buscada através do conceito $\mathrm{SCM}$, com a finalidade de que os processos de negócios transacionados entre os membros da cadeia de suprimentos fossem compartilhados para melhorar o fluxo de produtos e materiais, da extração da matéria-prima, passando pela entrega do produto final ao cliente e acabando no fluxo de retorno de materiais e produtos retornáveis. Figueiredo (2001) comenta a influência da logística integrada para a integração externa relacionada à gestão dos fluxos de materiais e informações ao longo da cadeia (de fornecedores a clientes finais). Para Bowersox e Closs (2001), a logística integrada "é vista como a competência que vincula a empresa a seus clientes e fornecedores". Nesse sentido, o conceito SCM tem sido empregado para melhorar a eficiência na gestão da cadeia de suprimentos e aumentar o nível de serviço demandado por todos os atores do arranjo, incluindo fornecedores, consumidores, atacadistas, varejistas, operadores logísticos, clientes finais, plantas industriais, entre outros.

$\mathrm{O}$ incremento na eficiência de uma cadeia de suprimentos passa necessariamente pela análise do valor gerado entre os elos do arranjo. Nesse sentido, avaliar as cadeias de valor dos membros tem sido uma alternativa ainda pouco usada na gestão da cadeia de suprimentos, no entanto, pode tornar-se uma ferramenta valiosa para verificar se as competências centrais dos integrantes do arranjo estão alinhadas para gerar valor aos diversos stakeholders interessados. Segundo Novaes (2004), "a cadeia de suprimentos é formada por uma sequência de cadeias de valor, cada uma correspondendo a cada uma das empresas que formam o sistema". De acordo com Koh e Nam (2005), uma cadeia de valor é uma série de atividades pelas quais promovem o valor, com ênfase no planejamento e coordenação dos negócios para se obter o melhor desempenho.

Alguns trabalhos já contribuem para reforçar a importância das cadeias de valor na gestão da cadeia de suprimentos (BOVET; MARTHA, 2000; KIRCHMER, 2004; TAYLOR, 2005; ZOKAEI; SIMONS, 2006; KOH et al., 2007). Portanto, o projeto e a gestão de uma cadeia de suprimentos devem considerar a integração das cadeias de valor no âmbito dos elos do arranjo.

Observações mostram que usualmente o projeto de uma cadeia de suprimento resulta de ações não sistematizadas estimuladas por ações reativas de seus membros em responder às demandas dos clientes e aos ataques concorrenciais, quando o projeto de gestão integrada da cadeia de suprimentos deveria ser desenvolvido e planejado para funcionar sustentavelmente e de maneira proativa às múltiplas demandas existentes. Por outro lado, o desenvolvimento de um projeto de gestão de uma cadeia de suprimentos prescinde de configuração, mapeamento e a integração de aspectos-chave, tais como os processos de negócios trocados entre integrantes.

A literatura evidencia que geralmente a configuração de uma cadeia atende a poucos requisitos, que usualmente não estão conectados entre si. Todavia, algumas contribuições têm sido observadas no sentido de melhor configurar uma cadeia de suprimentos (COOPER et al., 1997; LAMBERT et al., 1998; CROXTON et al., 2001).

Uma das justificativas deste artigo é a insuficiência de instrumentos adequados para configurar uma cadeia de suprimentos como base para o desenvolvimento de projetos SCM que integrem várias perspectivas, já que a gestão de uma cadeia de suprimentos deve assumir a existência de um grande número de interações trocadas entre seus integrantes, desde os fornecedores aos clientes finais. Outra perspectiva que não é integrada aos demais aspectos refere-se ao alinhamento dos vários objetivos presentes na cadeia de suprimentos. Notou-se que nos modelos (e.g. LAMBERT et al., 1998) para configurar a cadeia de suprimentos, o alinhamento não era tratado integradamente com outras perspectivas, tais como: nível de serviço; princípios SCM; tipo de abordagem de gestão necessária para conduzir de maneira eficiente os processos de negócios trocados entre os membros. 
Uma cadeia de suprimentos pode ser configurada de diversas maneiras, dependendo dos objetivos propostos. Entretanto, considerando uma perspectiva mais integrada e sistêmica, definiu-se como lacuna a seguinte questão de pesquisa: como configurar e integrar uma cadeia de suprimentos como base para o desenvolvimento de projetos SCM? Considerando o que foi exposto nessa seção e no intento de responder a essa lacuna, traçou-se como objetivo: propor um modelo analítico de suporte à configuração e integração da cadeia de suprimentos como base ao desenvolvimento e/ou melhoria de projetos SCM.

Portanto, a proposta do modelo busca oferecer subsídios para o aperfeiçoamento de projetos SCM com base num mapeamento contextualizado da cadeia de suprimentos. Assim, a configuração adequada do arranjo permite projetá-lo melhor para funcionar adequadamente no mercado de atuação. Na sequência, segue uma breve abordagem teórica sobre os temas tratados nesse artigo.

\section{Abordagem teórica}

Vários autores têm contribuído para definir uma cadeia de suprimentos (LA LONDE; MASTERS, 1994; CHRISTOPHER, 1997; MENTZER et al., 2001; THAKKAR et al., 2008). No insight de La Londe e Powers (1993), os autores prediziam que no século 21 o enfoque estaria em toda cadeia de suprimentos. Nesse sentido, sob a perspectiva sistêmica adaptou-se o seguinte conceito: conjunto agregado de cadeias de valor associadas por relações interorganizacionais que são estendidas a montante e jusante da empresa focal, com o propósito de processar os fluxos financeiro, de materiais, bens, serviços e informações, do primeiro fornecedor do fornecedor até o último cliente do cliente, tal como o fluxo reverso de componentes, produtos e materiais retornáveis, gerando valor ao cliente.

Uma empresa focal ou líder usualmente exerce alguma influência entre os membros, determinando muitas vezes o modo de coordenação da cadeia de suprimento. Na perspectiva da cadeia de suprimentos, as cadeias de valor podem formar um sistema de valores, que por sua vez está relacionado com o rol de atividades formado por elos a montante e a jusante do fabricante, sendo representados por fornecedores, distribuidores e varejistas. A Figura 1 ilustra as cadeias de valor distribuídas para formar o sistema de valores.

Para Porter (1989), a análise da cadeia de valor de cada empresa passa pela avaliação das atividades praticadas e pela forma como interagem na organização, para se compreender potenciais variáveis-chave de vantagens competitivas à entidade. Existem inúmeros conceitos sobre cadeia de valor (LUCHI; PALADINO, 2000; RAINBIRD, 2004; KOH; NAH, 2005; BUTLER et al., 2007).

Alguns conceitos expressam um conjunto de atividades de valor necessárias à produção e entrega de um bem ou serviço ao consumidor final. Outros abordam as atividades da empresa ao cliente, enquanto outras abordagens estendem as atividades de valor a montante e a jusante, todavia Porter (1989) deu origem ao conceito de uma cadeia genérica de valor, subdividida em várias atividades, conforme Figura 2.

A cadeia genérica de valor, segundo Porter (1989), representa as atividades de valor agregado geradas pela empresa para atender os requisitos demandados pelos consumidores sob a forma de produtos. Na Figura 2, o autor classifica as atividades de valor em primárias (logística interna, operações, logística externa, marketing e vendas e serviço) e de suporte (infraestrutura, gestão de recursos humanos, desenvolvimento de tecnologias e a aquisição de insumos/serviços). Como resultado do cruzamento entre as atividades, gera-se uma margem, conseguida através da subtração dos custos relacionados às atividades de valor do produto. A relação de interdependência entre as atividades resulta nos elos e liga as atividades de valor.

$\mathrm{O}$ estudo das cadeias de valor entre os membros da cadeia de suprimentos revela se os elos estão gerando o valor esperado pelos clientes finais e demonstra se as competências centrais dos membros (atividades de valor) são compatíveis, sincronizadas e complementares para maximizar o nível de serviço esperado. A análise das atividades de valor é relevante para a gestão da cadeia de suprimentos e viabilização do projeto SCM. Alguns autores destacam

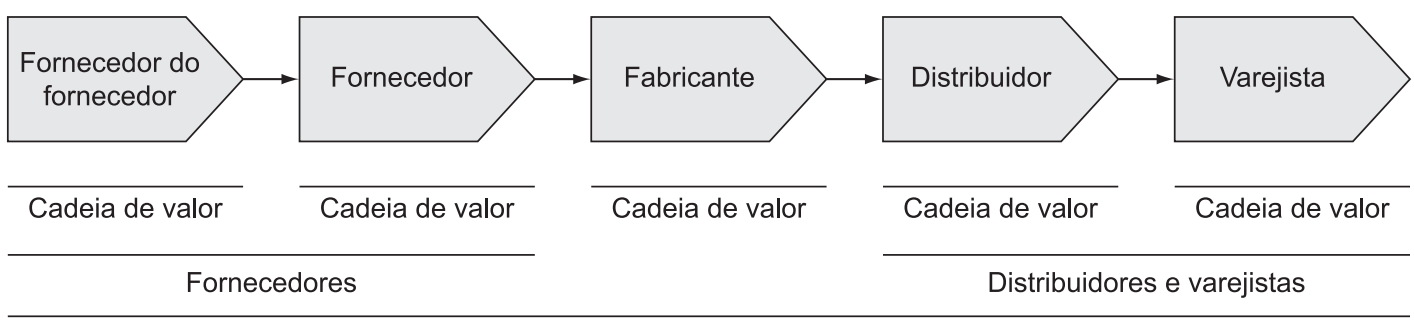

Sistema de valores

Figura 1. Cadeia genérica de valor. Fonte: Porter (1989). 


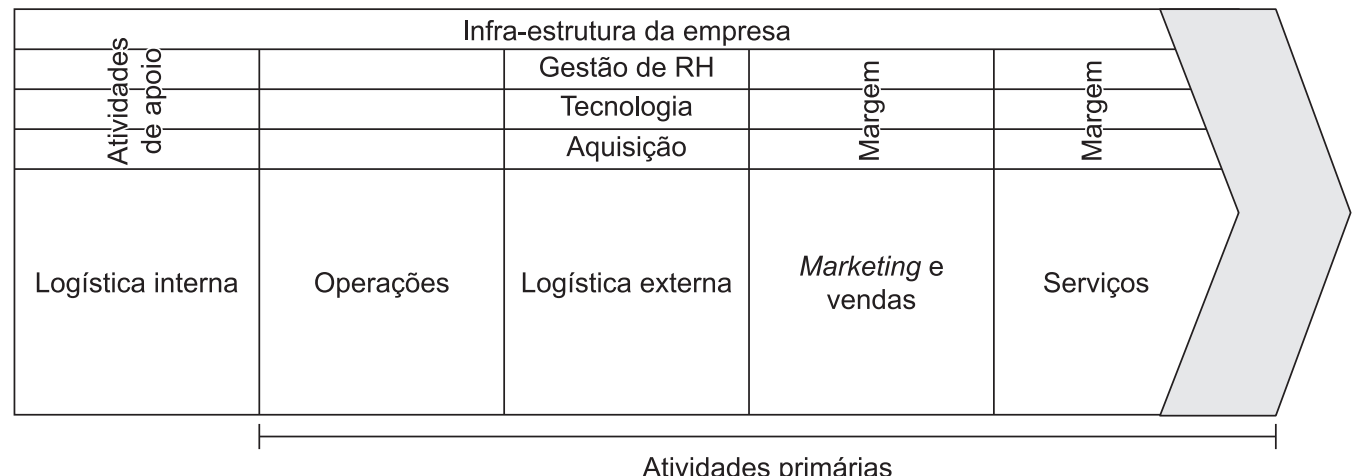

Atividades primárias

Figura 2. Subdivisão de uma cadeia genérica de valor. Fonte: Porter (1989).

a influência da logística integrada para o conceito SCM (CHRISTOPHER, 1997; CAVINATO, 1999; WOOD JR., 2004; BALLOU, 2006; CORONADO, 2007). Já Lambert et al. (1998) oferecem um escopo maior ao conceito SCM, tratando a logística como subgrupo de apoio aos processos de negócios extensos à cadeia de suprimentos e interligados por meio de fronteiras intra e interorganizacionais. Para Cooper et al. (1997) a integração de processos e atividades de negócios na cadeia logística extrapola a definição de logística.

É pertinente esclarecer quais as relações entre redes, cadeias de suprimentos, cadeias de valor e logística, considerando o que foi exposto nesta seção. Atualmente as redes são mais do que a simples junção de empresas, todavia uma forma de as organizações competirem para aumentar suas chances de sobrevivência no mercado. Assim, as redes podem ser formadas por diversas empresas, não sendo o fator geográfico impedimento para atuarem no mundo globalizado. Dentre os vários tipos de redes destacam-se alguns: consórcio modular, cadeia de suprimentos , arranjo produtivo local, entre outros.

As cadeias de suprimentos podem operar de maneira integrada em diversas partes do mundo, com clientes e fornecedores globalizados, bem como seus sistemas de produção através da terceirização (Globalsourcing). Não existem fronteiras espaciais para as grandes cadeias de suprimentos, como é o caso da Dell Computadores. Uma cadeia de suprimentos é formada por um conjunto de empresas estratégicas lideradas por uma empresa líder. Cada empresa componente contribui com suas competências centrais, as quais estão inseridas nas cadeias de valor das organizações arranjadas.

O conjunto de cadeias de valor das empresas componentes configura uma cadeia de suprimentos. Nesse sentido, esse conjunto pode ser constituído por fornecedores e clientes distribuídos globalmente no mundo em função do atendimento de necessidades mútuas. Nesse contexto, a logística integrada é a área de ligação entre as cadeias de valor, tendo como função primária integrar os processos de negócios que são executados no âmbito das cadeias de suprimentos, atuando do primeiro fornecedor do fornecedor ao último cliente do cliente, incluindo o retorno de produtos e materiais no fluxo reverso de produção.

O Council of Supply Chain Management Professionals ou CSCMP (2005) definiu que a gestão da cadeia de suprimentos (SCM) abrange o planejamento e gestão de todas as atividades envolvidas na obtenção e fornecimento, conversão e gerenciamento de todas as atividades logísticas. Incluem ainda a coordenação e colaboração com parceiros nos canais, podendo ser fornecedores, intermediários, provedores de serviços logísticos e clientes. Em essência, SCM integra a gestão do fornecimento e da demanda entre as empresas integrantes.

A gestão da cadeia de suprimentos pode atender a vários objetivos. Para Pires (2004) os objetivos SCM passam pela redução dos custos produtivos e maior agregação de valor ao produto através de um processo de gestão focado em toda a extensão da cadeia. Percepção também sustentada por Chopra e Meindl (2003), cujo objetivo de toda cadeia de suprimento é de maximizar o valor global gerado. Os objetivos de gestão de uma cadeia de suprimentos, para Chopra e Meindl (2003), devem estar alinhados com princípios de gestão, não obstante os diversos objetivos defendidos pelos membros da cadeia.

O alinhamento estratégico, para Chopra e Meindl (2003), significa que as estratégias, competitiva e da cadeia, têm objetivos comuns. Para os autores o alinhamento estratégico diz respeito à compatibilidade entre prioridades advindas do cliente, satisfeitas pela estratégia competitiva, e às habilidades da cadeia de suprimento, criadas pelas estratégias da cadeia.

Anderson et al. (2000) aplicaram uma pesquisa em cadeias de suprimentos, cujo objetivo foi identificar práticas de sucessos nesses arranjos. Os autores identificaram sete princípios: segmentação logística; customização do sistema logístico; previsão 
e percepção da demanda; postergação; gestão das fontes de suprimento; uso da tecnologia de informação e adoção de métricas de desempenho. Com esses princípios foi possível melhorar a eficiência no nível de serviço demandado pelos clientes. Larson (1998) sublinha que o resultado de um ou mais processos ou interfaces projetados para atender as expectativas do consumidor forma as bases dos serviços e do nível de serviço especificado.

A configuração de uma cadeia de suprimentos pode revelar interações e relações entre os membros. "Essas redes de configurações refletem os papéis e as atividades interconectadas dentro de uma cadeia de suprimento intraempresarial (McCORMACK; KASPER, 2002)". Diversos autores têm abordado a configuração da cadeia de suprimentos com ênfase na melhoria do processo de gestão. Segundo Pires et al. (2004), a análise das configurações deve representar o atual estágio de desenvolvimento da SCM, provendo potenciais oportunidades de melhorias no gerenciamento nos diversos elos, contribuindo para o processo de tomada de decisões. Para Lambert et al. (1998) conhecer explicitamente e compreender como a estrutura de rede da cadeia de suprimentos está configurada constitui fator-chave de gestão.

Nota-se que parte das abordagens não assume uma perspectiva integrada, focando-se em aspectos isolados da gestão. Os produtos encadeados em uma dada cadeia de suprimentos apresentam características que os credenciam a fluir numa cadeia mais adequada. Huang et al. (2002) classificam em: funcionais, inovadores e híbridos. Fisher (1997) criou um modelo conceitual para escolher estrategicamente a cadeia a partir da definição da natureza da demanda dos produtos ofertados pela empresa, classificando-os em funcionais e inovadores. Ele associa cadeias com processos fisicamente eficientes aos produtos funcionais, e as cadeias com processos responsivos ao mercado aos produtos inovadores. Os primeiros são produzidos para atender às necessidades básicas dos consumidores. Já os produtos inovadores representam as inovações incorporadas a eles, fazendo da demanda volátil e imprevisível (FISHER, 2007).

A análise das competências centrais dos integrantes na cadeia de suprimentos pode revelar a transferência de processos que não agregam valor a outros. Para McIvor (2003), as habilidades da empresa devem ser mantidas se elas servirem para sustentar uma vantagem competitiva, caso contrário devem ser negociadas com alianças estratégicas e relações cooperativas. Vollmann et al. (1996) classificaram as competências na cadeia em: distintivas, qualificadoras e básicas. A identificação da importância das competências permite às empresas estabelecerem as relações entre os processos de negócios com variados graus de proximidade entre parceiros.
Estudos realizados pelo Global Supply Chain Forum (COOPER et al., 1997, LAMBERT et al., 1998) identificaram oito processos-chave que orientam a análise das relações na cadeia de suprimentos (CROXTON et al., 2001): gestão da relação com o cliente; gestão de serviços ao cliente; gestão da demanda; atendimento dos pedidos; gestão do fluxo de produção; gestão da relação com os fornecedores; desenvolvimento e comercialização de produtos e gestão do retorno. O Supply Chain Council (2002) desenvolveu o modelo SCOR ou Supply Chain Operations Reference Model, constituído de cinco processos: planejamento, aquisição, fabricação, entrega e retorno (STEWART, 1997).

Para Lambert et al. (1998), três aspectos são importantes para descrever, analisar e gerenciar uma cadeia de suprimentos quanto à sua estrutura: a estrutura horizontal (número de níveis ao longo da cadeia); estrutura vertical (número de fornecedores/ clientes em cada nível) e a posição horizontal da empresa focal na cadeia de suprimentos (a empresa foco pode estar perto da fonte inicial de suprimento, próxima dos clientes finais, ou em alguma posição entre os pontos extremos da cadeia). Os membros de uma cadeia de suprimentos, para Lambert et al. (1998), podem ser classificados em primários e secundários.

Um membro primário é uma empresa autônoma a qual desempenha uma atividade operacional e/ou gerencial relativa aos processos de negócios projetados para produzir saídas específicas a um cliente ou mercado. Já um membro secundário fornece os conhecimentos, utilidades e recursos, entre outros, para que um integrante primário possa executar suas funções essenciais (LAMBERT et al., 1998). Os membros primários e secundários são conectados através de relações mantidas entre processos de negócios. Uma cadeia de suprimentos pode ser representada pela dinâmica de interações existentes entre os membros e os processos de negócios. Lambert et al. (1998) classificaram as relações estabelecidas entre os processos-chave em: relações gerenciadas; não gerenciadas; monitoradas; e com não membros. A Figura 3 mostra os níveis, a empresa focal, os não membros e a estrutura de relações entre os processos dos membros .

A flexibilidade nos sistemas de produção é abordada por Christopher (2000) através do suprimento ágil, que é capacidade de uma empresa responder rapidamente às mudanças na demanda, considerando volume e variedade. Já Naylor et al. (1999) destacam o suprimento enxuto contraposto ao suprimento ágil. O suprimento enxuto, segundo os autores, desenvolve um canal de valor para eliminar desperdício e habilitar um nível de programação.

A flexibilidade baseia-se na visão híbrida de abordagens enxutas e ágeis combinadas e integradas 


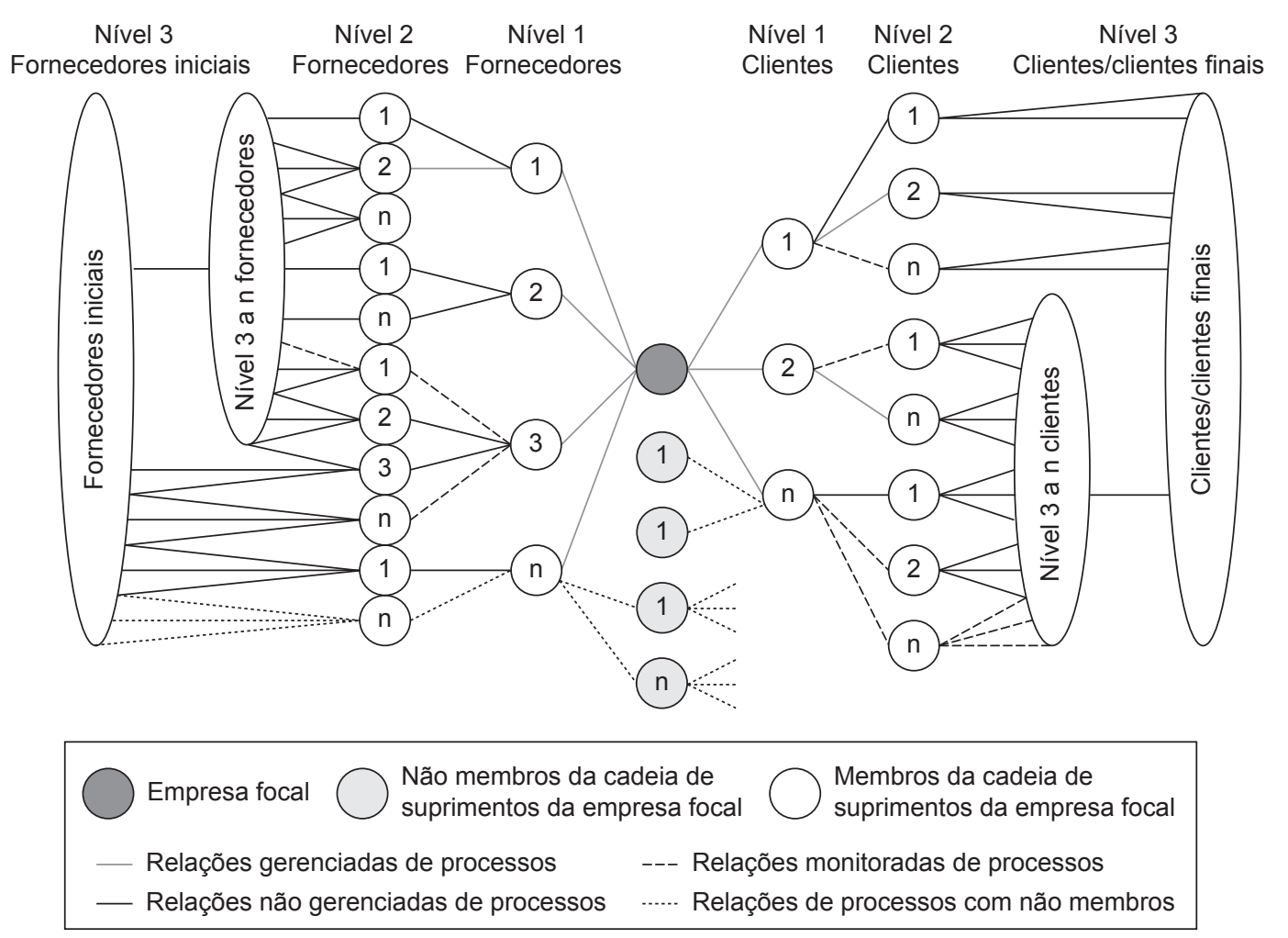

Figura 3. Relações de processos de negócios interempresariais. Fonte: Lambert et al. (1998).

em um ponto de decomposição para otimizar a cadeia de suprimentos (BRUCE et al., 2004). De acordo com Christopher (2000), a responsividade na cadeia de suprimentos está ligada ao atendimento rápido dos requisitos demandados pelo mercado.

Outra perspectiva bastante discutida na literatura sobre cadeia de suprimentos refere-se aos diversos tipos de relacionamentos e suas motivações. O grau de relação mantido por uma empresa focal e seus parceiros reflete o nível de integração e coordenação entre as empresas em função dos objetivos em comum celebrados na gestão de uma cadeia. A integração passa pelo aperfeiçoamento e comprometimento das parcerias. Cooper e Gardner (1993) destacam seis razões para explicar a consolidação de parcerias: necessidade; assimetria; reciprocidade; eficiência; estabilidade e legitimidade. Para Maheshwari et al. (2006), as parcerias numa cadeia de suprimentos representam uma coalizão estratégica entre duas ou mais empresas em uma cadeia de suprimentos. Segundo Whipple e Gentry (2000), quatro razões direcionam a consolidação das parcerias: financeiras; estratégicas; de gestão e tecnológicas. Já para Bowersox e Closs (2001), quatro causas promovem alianças: dependência mútua; clareza de poder; ênfase na cooperação e especialização central.

Quanto aos relacionamentos, Spekman et al. (1998) descreveram em: negociações em mercados abertos; cooperação; coordenação e colaboração. Já Lambert et al. (1996) comentam cinco relacionamentos: Arm's Lenght; tipo 1; tipo 2; tipo 3; Joint Ventures e integração vertical. Figueiredo, Fleury e Wanke (2006) conceberam, ao estudar embarcadores e provedores logísticos, três tipos de parcerias: o tipo 1 - parceria de curto prazo; tipo 2 - parceria de longo prazo; e o tipo 3 - parceria sem prazo limite.

Os ativos na cadeia de suprimentos podem ser compreendidos sob duas maneiras: os ativos tangíveis, segundo Bowersox e Closs (2001), representam o montante de investimentos em instalações e equipamentos com o objetivo de atender as metas logísticas preestabelecidas, além do investimento de capital de giro associado ao estoque; os ativos intangíveis, conforme Kaplan e Norton (1997), permitem que uma empresa desenvolva relacionamentos centrados na fidelidade dos clientes e atendimento de requisitos, produtos inovadores, customização de alta qualidade, a melhoria contínua e utilização potencial da tecnologia de informação.

Os membros da cadeia de suprimentos e seus processos de negócios são conectados por meio da interface entre os principais elos da cadeia. Essa interface se consolida em termos de fluxo de informação, cujo nível de eficiência associa-se ao processamento de informações. Para Chopra e Meindl (2003), "a informação serve como uma conexão 
entre os diversos estágios da cadeia de suprimentos, permitindo que possam coordenar suas ações e colocar em prática muitos dos benefícios de maximização da lucratividade total da cadeia".

As interfaces requerem quatro elementos: hardwares, softwares, gestores e operadores do sistema, e integração desses elementos no fluxo das informações na cadeia de suprimentos. A tecnologia da informação como recurso necessário ao processo de integração e interface da cadeia contribui para a consolidação dos procedimentos de comunicação (CHOPRA; MEINDL, 2003). Avaliar o desempenho da cadeia é outro aspecto relevante para aferir o cumprimento dos planos estratégicos, tema explorado por diversos autores (BITITCI et al., 1997; REY, 1998; HOLMBERG; DREYER, 2000; LAMBERT; POHLEN, 2001; MORGAN, 2004).

O desenvolvimento de projetos SCM pode ser realizado após a cadeia já vir operando (estando ou não formalizada) ou quando não existir nenhum planejamento prévio (no caso de as empresas se reunirem para projetar a cadeia e o modelo de gestão). Com base nas pesquisas literárias, os autores deste artigo desenvolveram o seguinte conceito para projetos SCM : é a concepção, planejamento, projeto, implantação e acompanhamento de um modelo de gestão construído com base na complexidade do ambiente de uma cadeia de suprimentos, buscando-se atingir e manter a integração e desempenho dos processos de negócios trocados entre os membros da rede. Assim, a proposta deste artigo atende a qualquer uma das condições, uma vez que ela fornece um panorama analítico do cenário de atuação das empresas, mesmo elas não participando de uma cadeia formalizada. A formalização da cadeia não implica diretamente na inexistência de um fluxo de produção. Os fluxos de suprimentos, transformação e distribuição existirão mesmo que a cadeia não seja formalizada.

Autores como Bechtel e Jayaram (1997) e Mentzer et al. (2001) propuseram, partindo de análises empíricas em cadeias de suprimentos, abordagens para explicar as modalidades de gestão empregadas na cadeia. O tipo de gerenciamento praticado na condução de uma dada cadeia de suprimentos pode estar associado ao conceito percebido pela empresa líder e membros do que seja a gestão da cadeia de suprimentos. Mentzer et al. (2001) apresentam três lógicas pelas quais os diversos conceitos de SCM se enquadram, tentando estabelecer um tipo de abordagem gerencial o qual reflita os conceitos introduzidos por vários autores (Van HOEK et al., 2001; BRUCE et al., 2004; BALLOU, 2006) . Assim, o termo SCM pode traduzir uma filosofia gerencial, a implantação dessa filosofia ou um conjunto de processos de gestão. Bechtel e Jayaram (1997) propuseram um modelo conceitual das diversas abordagens sobre SCM identificando cinco tipos de abordagem: perceptiva da cadeia; de vínculo; da informação; da integração e futura.

A configuração da cadeia de suprimentos, dependendo do instrumento a ser utilizado para esse fim, pode determinar o tipo de gestão dado à cadeia, mesmo esta não sendo formalizada. Portanto, a configuração e mapeamento integrado da cadeia de suprimentos é condição necessária à construção ou aperfeiçoamento dos projetos SCM. Por fim, o mapeamento das relações em uma cadeia de suprimentos permite gerar condições de melhorar o desempenho e aumentar a confiabilidade entre empresas do arranjo (LEE et al., 2007).

\section{Aspectos metodológicos}

A Figura 4 ilustra os aspectos metodológicos utilizados neste artigo. A natureza desta pesquisa foi básica, uma vez que se desenvolveu um instrumento teórico sem que a aplicação prática fosse realizada. Inicialmente foi feita uma revisão de literatura com a finalidade de aprofundar as discussões em torno da configuração das cadeias de suprimentos e de conceitos SCM. A pesquisa bibliográfica de caráter exploratório e descritivo buscou também verificar como os autores da área tratavam os temas: projetos SCM e configuração e mapeamento das cadeias. A estrutura conceitual foi construída com base em dados de natureza qualitativa e proporcionou fundamentos necessários à construção do modelo proposto. Segundo Silva e Menezes (2001), a pesquisa qualitativa é um vínculo indissociável entre o mundo objetivo e a subjetividade do sujeito que não pode ser traduzido em números.

De acordo com a Figura 4, iniciou-se o estudo a partir do tema configuração da cadeia de suprimentos acerca dos projetos SCM, o qual alicerçou o desenvolvimento da pesquisa. Dessa forma, a natureza do trabalho foi caracterizada como uma pesquisa básica, conforme mencionado. Assim, a pesquisa básica se apoiou na produção de um modelo analítico para configurar a cadeia de suprimentos aplicando o desenvolvimento de projetos SCM, de forma a representar a estrutura conceitual do trabalho, uma vez que se produziu uma base teórica para a produção do modelo proposto apoiado em uma revisão de literatura. O problema abordado assume características qualitativas, já que não envolve dados matemáticos ou estatísticos. Os autores da pesquisa definiram o seguinte problema: como configurar e integrar uma cadeia de suprimentos como base para o desenvolvimento de projetos SCM? No sentido de solucionar esse problema delimitou-se um objetivo, descrito na seção 1 .

Quanto ao objetivo proposto, essa pesquisa é exploratória e descritiva, ou seja, houve um rastreamento bibliográfico e descrição do estado 


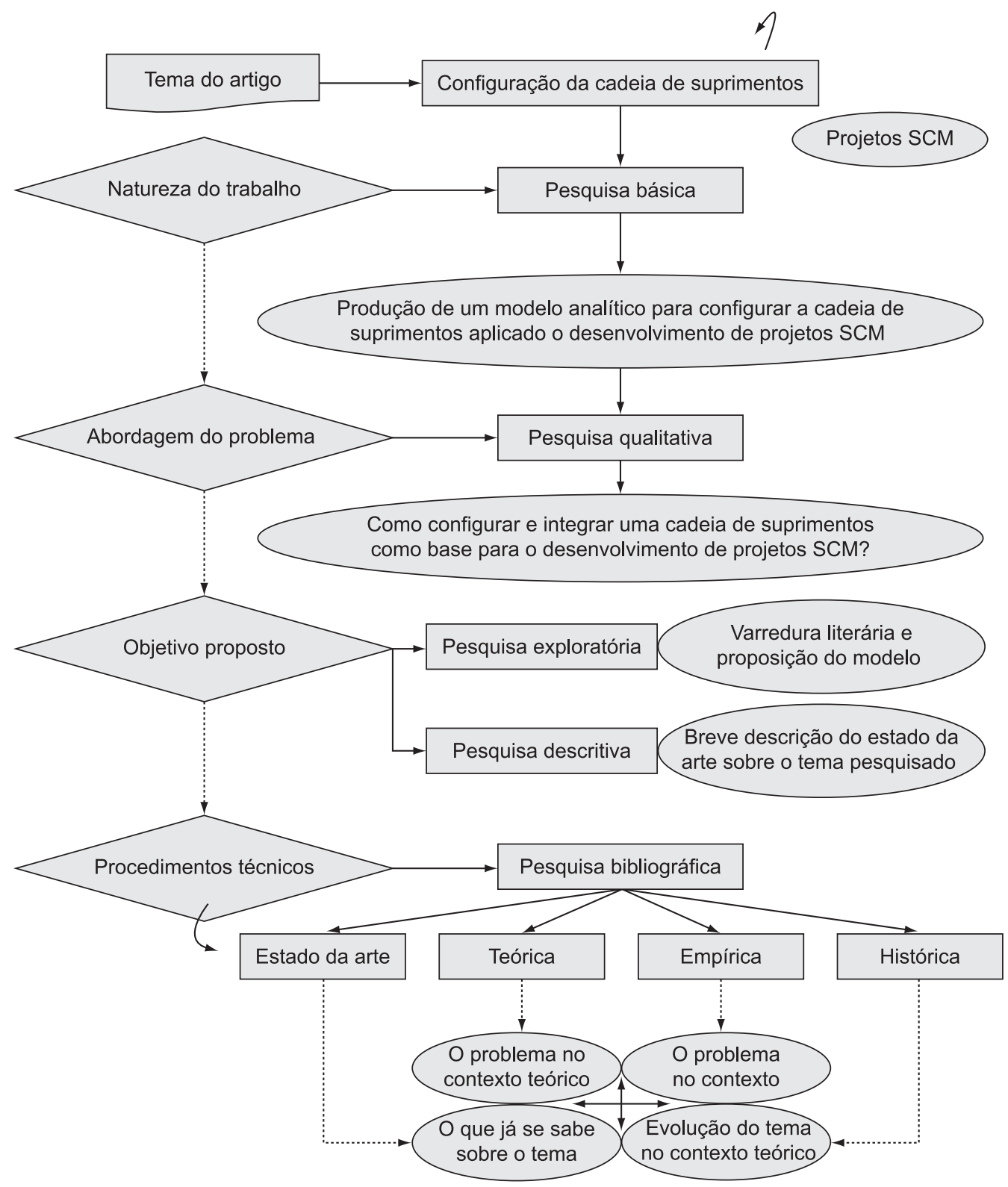

Figura 4. Síntese dos procedimentos técnicos. Fonte: Elaboração dos autores, 2008.

da arte do tema de pesquisa. De acordo com Gil (2006), a pesquisa exploratória tem por objetivo proporcionar maior familiaridade com o problema a fim de torná-lo explícito ou construir hipóteses. Ainda segundo o autor, a pesquisa descritiva visa descrever as características de determinada população ou fenômeno, ou o estabelecimento de relações entre variáveis. Para atingir o objetivo dessa pesquisa, alguns procedimentos técnicos foram usados, tais como pesquisa bibliográfica e revisão da literatura. Estas duas técnicas foram segmentadas nas seguintes etapas de pesquisa: do estado da arte, buscando-se verificar o conhecimento sobre o tema; histórica, por meio de uma análise da evolução do tema no contexto da pesquisa; teórica, a partir da contextualização do problema na perspectiva literária; e empírica, estudando-se o problema no contexto metodológico. Os resultados desta pesquisa são apresentados na sequência, seguidos das discussões.

\section{Apresentação e discussão dos resultados}

Nesta seção são apresentados e discutidos os resultados gerados através da pesquisa realizada neste artigo. Inicialmente apresenta-se um framework 
explicando como os conceitos foram usados na proposição do modelo. Posteriormente, a sistemática proposta para configurar a cadeia de suprimentos é ilustrada e discutida. Na sequência, segue-se o modelo desenvolvido para mapeamento da cadeia de valor, o qual foi incorporado ao modelo de configuração da cadeia de suprimentos. O Quadro 1 resgata os conceitos abordados no modelo e seus autores.

O Quadro 2 demonstra como os conceitos foram aplicados para embasar a construção do modelo de configuração da cadeia de suprimentos, integrando várias perspectivas descritas no Quadro $1 \mathrm{com} o$ auxílio da revisão de literatura.

\section{Descrição do modelo analítico}

Nesta seção, o modelo analítico destinado a apoiar o processo de configuração da cadeia de suprimentos é apresentado e discutido, conforme Figura 5. Nesse sentido, dez perspectivas devem ser exploradas para se analisar integradamente as interações provenientes da operação da cadeia de suprimentos, quais sejam: produtos; competências; processos; relações; estrutura; flexibilidade; desempenho; relacionamentos; ativos; e interfaces. Os objetivos na cadeia também devem ser levantados (objetivos da cadeia, de cada empresa e dos clientes finais). Os objetivos são confrontados com as interações originadas das perspectivas no sentido de verificar se há um alinhamento estratégico.

Por sua vez, o alinhamento estratégico deve ser confrontado com a cadeia de valor de cada membro-chave da cadeia de suprimentos. O objetivo é verificar se existem sincronia e complementação entre as competências centrais de cada membro-chave na geração de valor aos elos componentes da cadeia de suprimentos. Com o levantamento das cadeias de valor dos membros, é possível verificar se há a formação de um sistema de valor comprometido com a elevação do nível de serviço ao cliente final a um custo adequado. Mapeadas as inter-relações originadas das perspectivas, observado o alinhamento estratégico e configuradas as cadeias de valor, pode-se verificar quais os princípios SCM são aplicados na cadeia de suprimentos, tanto a montante (upstream), como a jusante (downstream).

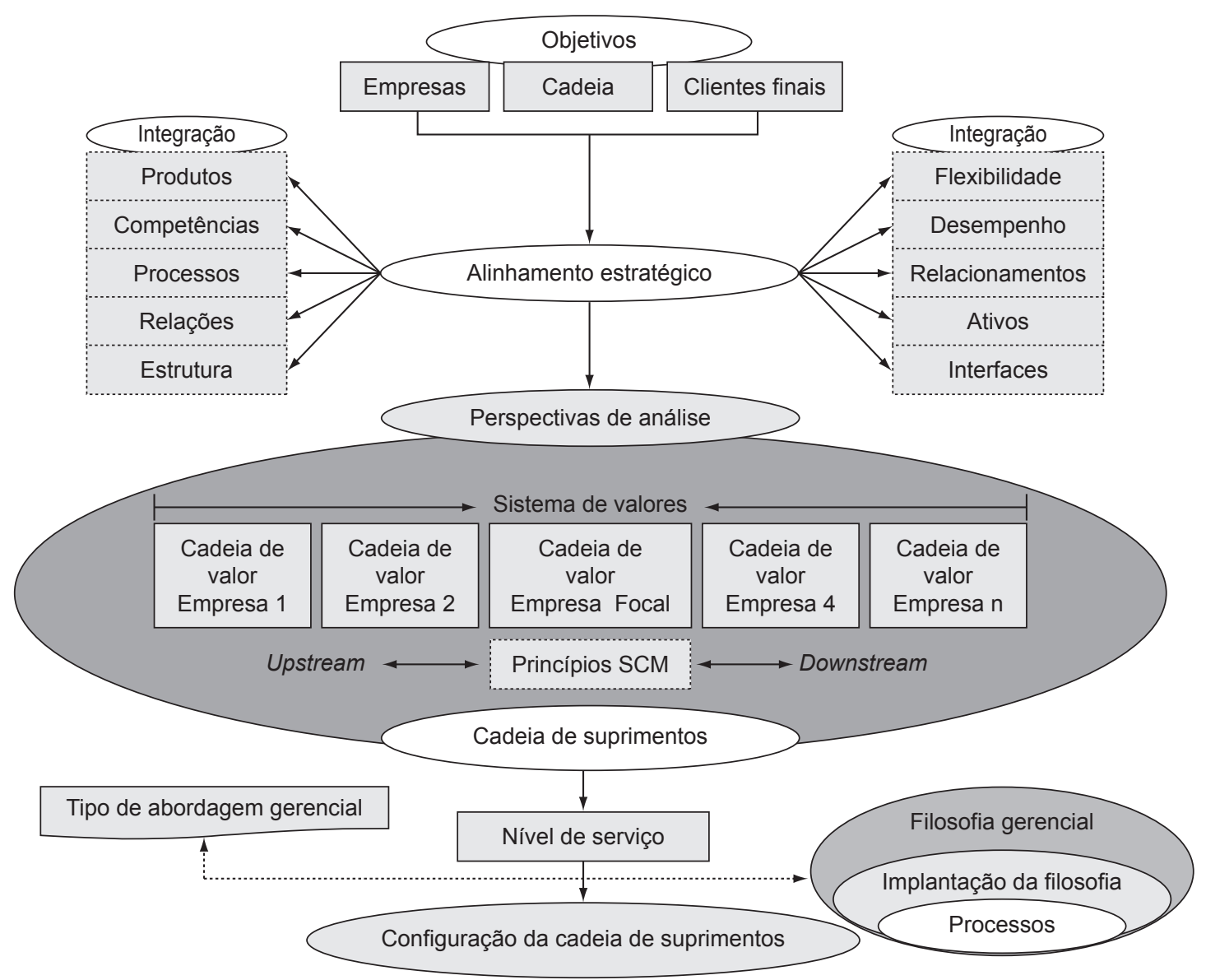

Figura 5. Modelo analítico de configuração da cadeia de suprimentos. Fonte: Elaboração dos autores (2008). 
Quadro 1. Resgate dos conceitos usados na construção do modelo proposto. Fonte: Elaboração dos autores (2008).

\begin{tabular}{|lll}
\hline Conceito & Representação & Autores
\end{tabular}

Cadeia de suprimentos

Sistema de valores

Cadeia de valor

SCM

Objetivos SCM

Grupo de cadeias de valor ligadas intraorganizacionalmente a montante e a jusante da empresa focal para processar os fluxos do primeiro fornecedor do fornecedor ao último cliente do cliente, gerando valor ao cliente.

Adaptado de Porter (1989); Lambert, Cooper e Pagh (1998)

O rol de atividades formado por elos a montante e a jusante do fabricante, Porter (1989) sendo representados por fornecedores, distribuidores e varejistas.

Alinhamento estratégico

Princípios SCM

Nível de serviço

Representação das atividades de valor geradas pela empresa para atender os requisitos demandados pelos consumidores e na forma de produtos.

Planejamento e gestão de todas as atividades envolvidas na obtenção e fornecimento, conversão e a gestão de todas as atividades logísticas, incluindo a coordenação e colaboração com parceiros nos canais.

Redução dos custos produtivos e maior agregação de valor ao produto através de um processo de gestão focado em toda a extensão da cadeia.

Configuração da cadeia

Produtos

Competências

Compatibilidade entre prioridades do cliente (satisfeitas pela estratégia competitiva) e habilidades da cadeia (criadas pelas estratégias da cadeia).

Práticas de sucessos na gestão de cadeias traduzidas em princípios.

Resultado de um ou mais processos ou interfaces projetados para atender às expectativas do consumidor.

A análise das configurações deve representar o atual estágio de desenvolvimento da SCM, provendo potenciais oportunidades de melhorias na gestão nos diversos elos, contribuindo para a tomada de decisões.

Associa cadeias com processos fisicamente eficientes a produtos funcionais e cadeias com processos responsivos ao mercado aos produtos inovadores.

(1)

Processos de negócios

Relações entre processos

Estrutura da cadeia

Flexibilidade no suprimento

Relacionamentos de parceria

Interfaces entre elos

Ativos

Desempenho

Lógicas de gestão
A identificação da importância das competências permite às empresas estabelecer relações com graus variados de proximidade entre parceiros.

Processos trocados entre os membros da cadeia de suprimentos.

Relações que ligam os membros aos processos de negócios em função da importância para a empresa focal (líder).

A estrutura da cadeia pode ser configurada verticalmente, horizontalmente e por meio do posicionamento da empresa focal na cadeia.

Visão híbrida dessas abordagens enxutas e ágeis combinadas e integradas em um ponto de decomposição para otimizar a cadeia de suprimentos.

O tipo de relacionamento mantido pela empresa focal e seus parceiros reflete o nível de integração e coordenação entre as empresas em função dos objetivos em comum celebrados na gestão da cadeia.

Os membros da cadeia de suprimentos e seus processos de negócios são conectados por meio da interface consolidada em termos de fluxo de informação, cujo nível de eficiência está associado ao seu processamento.

Os ativos intangíveis relacionam-se à gestão de aspectos qualitativos que geram valor aos membros, colaboradores e clientes finais da cadeia, enquanto os ativos tangíveis representam investimentos em instalações e equipamentos e capital de giro associado ao estoque.

Necessidade de mensurar e avaliar o desempenho dos elos em relação ao cumprimento dos planos estratégicos para estabelecer melhorias ao processo.

A aplicação do conceito SCM pode se enquadrar em um tipo de gestão.
Porter (1989)

CSCMP (2005)

Pires (2004)

Chopra e

Meindl (2003)

Anderson, Britt e Favre (2000)

Larson (1998)

Pires (2004)

Fisher (1997)

Vollmann, Cordon e

Raabe (1996)

Stewart (1997)/SCOR

Lambert, Cooper e Pagh (1998)

Lambert, Cooper e Pagh (1998)

Naylor, Naim e Berry (1999); Christopher (2000); Bruce, Daly e

Cooper e Gardner (1993); Spekman, Kamauff Jr. e Myhr (1998)

Chopra e

Meindl (2003)

Kaplan e Norton (1997); Bowersox e Closs (2001)

Supply Chain Council (2002)

Mentzer et al. (2001) Towers (2004) 
Quadro 2. Aplicação dos conceitos usados na construção do modelo proposto. Fonte: Elaboração dos autores (2008).

\begin{tabular}{|c|c|}
\hline Conceito & Framework de aplicação do conceito \\
\hline Cadeia de suprimentos & $\begin{array}{l}\text { Escolher a cadeia como objeto de estudo e verificar se o conjunto de cadeias de valor } \\
\text { distribuídas a montante e a jusante da empresa focal está gerando o valor esperado pelos } \\
\text { clientes. }\end{array}$ \\
\hline Sistema de valores & $\begin{array}{l}\text { Identificar se as cadeias de valor dos membros da cadeia de suprimentos e suas } \\
\text { atividades primárias e secundárias formam um sistema de valores a montante e a jusante } \\
\text { da empresa focal. }\end{array}$ \\
\hline Cadeia de valor & $\begin{array}{l}\text { Levantar a cadeia de valor dos membros-chave da cadeia de suprimentos para verificar } \\
\text { se as competências centrais estão alinhadas e sincronizadas em torno dos objetivos da } \\
\text { cadeia. }\end{array}$ \\
\hline $\mathrm{SCM}$ & $\begin{array}{l}\text { Verificar como o conceito SCM vem sendo praticado e compreendido pelos membros- } \\
\text { chave da cadeia de suprimentos. }\end{array}$ \\
\hline Objetivos SCM & $\begin{array}{l}\text { Levantar os objetivos da cadeia como um todo, dos clientes finais e dos membros } \\
\text { principais da cadeia de suprimentos, inclusive a empresa focal (líder). }\end{array}$ \\
\hline Alinhamento estratégico & $\begin{array}{l}\text { Verificar se os objetivos mencionados estão alinhados com o nível de serviço exigido } \\
\text { pelos clientes finais e pelos membros-chave da cadeia de suprimentos. }\end{array}$ \\
\hline Princípios SCM & $\begin{array}{l}\text { Mapear quais os princípios utilizados pelos membros a partir da configuração das } \\
\text { perspectivas-chave. }\end{array}$ \\
\hline Nível de serviço & $\begin{array}{l}\text { Mensurar o nível de serviço resultante dos esforços da cadeia de suprimentos em atender } \\
\text { à demanda dos clientes finais a jusante da empresa focal. }\end{array}$ \\
\hline Configuração da cadeia & $\begin{array}{l}\text { Sistematizar subsídios relevantes para o desenvolvimento de projetos SCM com base na } \\
\text { configuração de perspectivas-chave na cadeia de suprimentos. }\end{array}$ \\
\hline Produtos & $\begin{array}{l}\text { Verificar se a cadeia de suprimentos é adequada para suportar o fluxo dos produtos } \\
\text { transacionados. }\end{array}$ \\
\hline Competências & $\begin{array}{l}\text { Identificar os tipos de competências dos membros-chave. A cadeia de valor pode } \\
\text { instrumentar essa ação. }\end{array}$ \\
\hline Processos de negócios & $\begin{array}{l}\text { Levantar os processos de negócios transacionados entre os membros da cadeia de } \\
\text { suprimentos. }\end{array}$ \\
\hline $\begin{array}{l}\text { Relações entre } \\
\text { processos }\end{array}$ & $\begin{array}{l}\text { Classificar, a partir dos processos-chave levantados, os tipos de relações estabelecidas } \\
\text { entre os processos de negócios e os membros. }\end{array}$ \\
\hline Estrutura da cadeia & $\begin{array}{l}\text { Mapear a estrutura física (instalações, centros de distribuição, plantas industriais) e } \\
\text { virtual dos membros (primários, secundários, horizontal, vertical e empresa foco). }\end{array}$ \\
\hline $\begin{array}{l}\text { Flexibilidade no } \\
\text { suprimento }\end{array}$ & $\begin{array}{l}\text { Pesquisar qual o tipo predominante de suprimento realizado entre os elos da cadeia, ou } \\
\text { se os tipos de abordagens combinam entre si. }\end{array}$ \\
\hline $\begin{array}{l}\text { Relacionamentos de } \\
\text { parceria }\end{array}$ & $\begin{array}{l}\text { Descrever os tipos de relacionamentos de parcerias estabelecidas entre os membros- } \\
\text { chave na cadeia. }\end{array}$ \\
\hline Interfaces entre elos & $\begin{array}{l}\text { Levantar quais os principais mecanismos de interface entre os membros da cadeia e qual } \\
\text { o nível de desenvolvimento tecnológico aplicado nas conexões entre os membros com } \\
\text { ênfase na informação. }\end{array}$ \\
\hline Ativos & $\begin{array}{l}\text { Mapear os principais ativos tangíveis e intangíveis inseridos na cadeia de suprimentos, } \\
\text { verificando a importância dada pelos membros a esses aspectos. }\end{array}$ \\
\hline Desempenho & $\begin{array}{l}\text { Verificar como os membros da cadeia de suprimentos mensuram e avaliam o } \\
\text { desempenho de seus processos de negócios. }\end{array}$ \\
\hline Lógicas de gestão & $\begin{array}{l}\text { Definir, a partir da interação entre os vários conceitos contidos nesse Quadro, o } \\
\text { tipo predominante de gestão praticado na cadeia de suprimentos considerando os } \\
\text { fundamentos dos conceitos SCM. }\end{array}$ \\
\hline
\end{tabular}


O nível de serviço representa os resultados dos esforços da cadeia de suprimentos em atender aos objetivos estratégicos que usualmente podem ser influenciados pelas demandas e requisitos dos clientes finais. O nível de serviço pode ser então comparado com o alinhamento estratégico e com as interações que foram analisadas em função das perspectivas estudadas. Por fim, para fechar a configuração da cadeia, os resultados da análise de todos esses aspectos geram insights para determinar o tipo de abordagem gerencial aplicada na cadeia: a gestão é baseada nas trocas entre os processos de negócios; se a gestão foca-se na implantação da filosofia do conceito SCM; ou se os membros-chave evoluíram ao ponto de considerar a gestão das empresas arranjadas como integrada, distintiva e única para todos os integrantes.

As cadeias de valor dos membros-chave podem ser configuradas de acordo com um modelo desenvolvido para os fins desse artigo, conforme Figura 6. O levantamento da cadeia de valor de um membro na cadeia de suprimentos passa pela identificação do que é valor para os membros (produto, conhecimento, clientes, processos e outros). Baseado no que a empresa considere estrategicamente como valor, parte-se para mapear as atividades organizacionais com base nas competências centrais ou essenciais de cada empresa. Isso é feito por meio do estabelecimento de critérios para hierarquizar as atividades mais relevantes para a empresa com base na importância. Das atividades classificadas em primárias e secundárias, verificam-se quais dessas últimas foram subcontratadas. Gera-se uma matriz que correlaciona atividades à estrutura da empresa, produzindo a dinâmica das interações entre atividades estratégicas e de apoio. Essas atividades podem ser comparadas com as competências centrais para verificar se há alinhamento entre as atividades. Assim, configuram-se as atividades centrais. Já na sequência, o modelo analítico ilustrado na Figura 5 é explodido, mostrando em detalhes seus componentes, como mostrado na Figura 7.

Conforme a Figura 7, dada a configuração a ser realizada da cadeia de suprimentos, procede-se a identificação da empresa focal (líder) e dos membroschave por meio de critérios qualificadores com a finalidade de se definir quem lidera a cadeia. Logo após, identifica-se o escopo da cadeia, tanto no sentido a montante (fornecedores), como a jusante (clientes finais), no sentido de definir o ponto de origem (upstream) e o ponto de corte (downstream), ou seja, onde se iniciam e terminam os elos da cadeia. Nessa mesma ação procede-se o levantamento da quantidade e especificação dos níveis ou elos e o número de empresas em cada elo. Com os limites da cadeia, dos membros-chave e da empresa líder, parte-se para a configuração das cadeias de valor desses integrantes (modelo ilustrado na Figura 6), analisando-se as atividades-chave e competências centrais dos membros com relação ao alinhamento das cadeias de valor.

A partir da identificação da empresa líder e dos membros-chave, busca-se levantar os objetivos dos membros da cadeia (há um objetivo geral de gestão; os membros apresentam objetivos de gestão distintos; os objetivos são direcionados pelo cliente final). Isso pode ser realizado verificando-se o alinhamento estratégico entre os objetivos, que por sua vez deverá ser comparado com as interações extraídas da exploração das dez perspectivas de

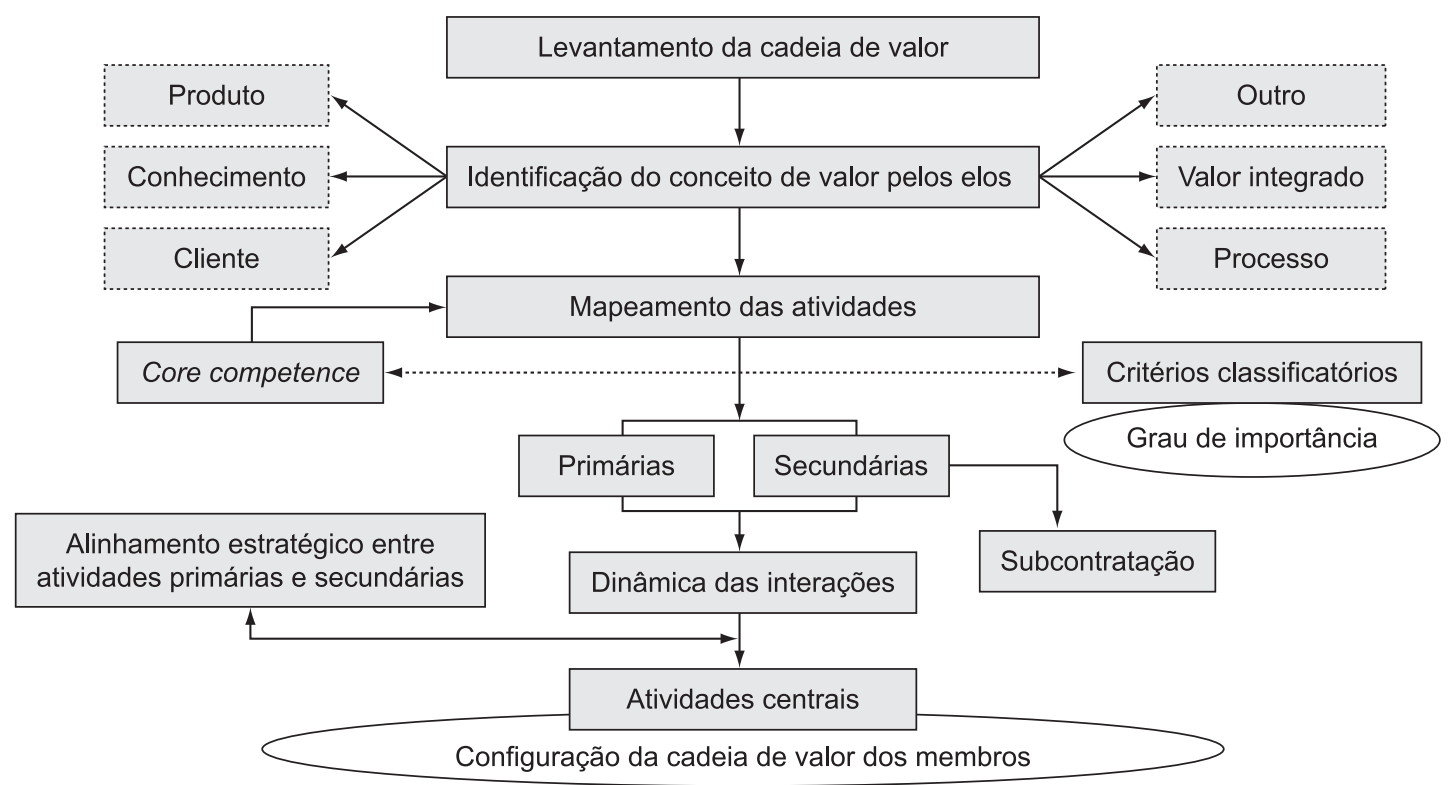

Figura 6. Modelo de configuração da cadeia de valor dos membros. Fonte: Elaboração dos autores (2008). 





Quadro 3. Síntese dos aspectos conceituais usados no modelo proposto. Fonte: Elaboração dos autores (2008).

\begin{tabular}{|c|c|}
\hline Conceito & Finalidade \\
\hline Objetivos estratégicos & $\begin{array}{l}\text { Levantar os objetivos estratégicos das empresas componentes, da cadeia e dos } \\
\text { clientes finais, no intuito de confrontar com as perspectivas de análise. }\end{array}$ \\
\hline Perspectivas de análise & $\begin{array}{l}\text { Analisar a cadeia de suprimentos de acordo com dez perspectivas, gerando-se as } \\
\text { interações necessárias e confrontando-as com os objetivos estratégicos. }\end{array}$ \\
\hline Alinhamento estratégico & $\begin{array}{l}\text { Verificar se existe um alinhamento estratégico entre a definição dos objetivos } \\
\text { estratégicos e as interações extraídas da análise das perspectivas em função da } \\
\text { sincronização e complementação das competências centrais de cada membro na } \\
\text { geração de valor aos elos da cadeia. }\end{array}$ \\
\hline Cadeias de valor & $\begin{array}{l}\text { Mapear as cadeias de valor dos membros-chave da rede, ou seja, as competências } \\
\text { centrais. }\end{array}$ \\
\hline Sistema de valores & $\begin{array}{l}\text { Avaliar se as cadeias de valor, de acordo com suas competências centrais, formam } \\
\text { um sistema de valores. }\end{array}$ \\
\hline Princípios SCM & $\begin{array}{l}\text { Rastrear quais princípios de gestão da cadeia de suprimentos (SCM) são usados na } \\
\text { rede, tanto a montante, como a jusante da empresa líder. }\end{array}$ \\
\hline Nível de serviço & $\begin{array}{l}\text { Verificar se o nível de serviço representa os esforços da cadeia de suprimentos } \\
\text { em atender aos objetivos estratégicos. Dessa forma, pode ser comparado com o } \\
\text { alinhamento estratégico e com as perspectivas analisadas. }\end{array}$ \\
\hline Tipo de abordagem gerencial & $\begin{array}{l}\text { Definir o tipo de abordagem gerencial praticado na cadeia de suprimentos em } \\
\text { função da análise dos aspectos estudados nas fases anteriores do modelo. }\end{array}$ \\
\hline $\begin{array}{l}\text { Configuração da cadeia de } \\
\text { suprimentos }\end{array}$ & $\begin{array}{l}\text { A execução das etapas anteriores gera a configuração da cadeia de suprimentos } \\
\text { como base para a proposição ou melhoria de projetos SCM. }\end{array}$ \\
\hline
\end{tabular}

análise. Em seguida procede-se ao levantamento e análise das perspectivas na cadeia de suprimentos. Esse mapeamento de interações deve ser realizado de modo integrado, buscando correlacionar as perspectivas entre si. Devem ser observados aspectos como compartilhamento, integração, comprometimento e colaboração entre as perspectivas.

As interações no estudo das perspectivas, do alinhamento estratégico e configuração das cadeias de valor permitem visualizar os princípios SCM predominantes na cadeia. Todos os esforços, táticos, estratégicos e operacionais na execução dos processos de negócios entre os membros da cadeia de suprimentos resultam em um nível de serviço oferecido aos clientes finais e também aos membros de cada elo. É nesse momento que os aspectos analisados na cadeia de suprimentos podem ser sistematizados e correlacionados entre si com o objetivo de definir o tipo de abordagem gerencial SCM praticada pelos membros da cadeia. A partir dos resultados da análise das perspectivas, são identificados aspectos críticos que agregam valor à cadeia. Assim, esses aspectos podem então ser analisados: configuração das cadeias de valor; alinhamento estratégico; mapeamento de análise das perspectivas; princípios SCM que são mais predominantes; mensuração e avaliação dos níveis de serviços.

Analisadas as interações mencionadas, pode-se definir o tipo de abordagem gerencial dada a cadeia de suprimentos (filosofia, implantação da filosofia, processos de negócios). Com isso pode-se, a partir da arquitetura da cadeia, identificar necessidades potenciais de melhoria.

\section{Considerações finais}

Este artigo, partindo de uma revisão de literatura, propôs um modelo analítico para auxiliar na configuração e integração de perspectivas-chave inseridas no contexto das cadeias de suprimentos. $\mathrm{O}$ modelo proposto oferece subsídios relevantes para o desenvolvimento de projetos SCM com base em um mapeamento contextualizado da cadeia de suprimentos. Nesse sentido, um projeto eficiente de gestão da cadeia de suprimentos precede a análise integrada desta, considerando a sua extensão e o nível de interações estabelecidas entre os membros do arranjo. Quanto a esse aspecto, o modelo, caso seja validado na prática, poderá subsidiar o desenvolvimento de projetos ou aperfeiçoar os processos de gestão através de intervenções mais adequadas e sustentáveis, asseguradas pela configuração de perspectivas-chave responsáveis pela dinâmica da cadeia de suprimentos. O Quadro 3 sintetiza os aspectos conceituais usados no modelo de configuração da cadeia de suprimentos e suas finalidades.

O modelo proposto pode contribuir para o avanço das pesquisas na área de cadeias de suprimentos, já que os conceitos estabelecidos ainda estão em vias de aperfeiçoamentos e por se tratar de um campo de exploração relativamente novo. Assim, a proposição destaca a necessidade de uma compreensão mais integrada e contextualizada da cadeia de suprimentos, 
com a finalidade de melhorar os processos de gestão e fazer com que ela se adapte rapidamente às mudanças no seu ambiente de atuação, uma vez que o modelo oferece uma representação das interações que agregam mais valor aos membros do arranjo.

No âmbito da Engenharia de Produção, o artigo contribui a partir da apresentação de um arcabouço teórico sistematizado em uma ferramenta, cujo fim é contribuir para a redução dos problemas produzidos pela formação de arranjos empresariais, especialmente as cadeias de suprimentos. Nesse sentido, o modelo poderá facilitar a identificação de barreiras e limitações que comprometam a eficiência na gestão da cadeia. Assim, é possível diminuir a distância entre o segmento empresarial e acadêmico, no sentido de se construírem soluções colaborativas para resolver questões que requeiram um esforço de pesquisa bilateral e multidisciplinar.

Recomenda-se validar o modelo por outros pesquisadores, já que há a pretensão de também validá-lo aplicando-se os resultados teóricos em uma cadeia já formalizada. Outra recomendação é que novas perspectivas de análise possam ser inseridas, como a governança, ou substituídas por outras abordagens. Assim, os resultados teóricos produzidos neste artigo e traduzidos no modelo analítico contribuem para compreender e representar (dados certos limites) a complexidade presente no contexto das cadeias, sugerindo meios para melhorar os projetos SCM, na medida em que se produza uma configuração mais integrada das interações.

\section{Referências}

ANDERSON, D. L.; BRITT, F. E.; FAVRE, D. J. The seven principles of supply chain management. 1997. Disponível em: <http://www.manufacturing.net/ magazine/logistic/archives/1997/scmr/11 princ.htm>. Acesso em: 15 jan. 2006.

BALlOU, R. H. Gerenciamento da Cadeia de Suprimentos/Logística Empresarial. Porto Alegre: Bookman, 2006.

BECHTEL, C.; JAYARAM, J. Supply Chain Management: a strategic perspective. International Journal of Logistics Management, v. 8, n. 1, p. 15-34, 1997.

BITITCI, U. S.; CARRIE, A. S.; McDEVITT, L. Integrated performance measurement systems: a development guide. International Journal of Operations \& Production Management, v. 17, n. 5, p. 522-534, 1997.

BOVET, D.; MARTHA, J. Value nets: reinventing the rusty supply chain of competitive advantage. Strategy \& Leadership, v. 28, n. 4, p. 21-26, 2000.

BOWERSOX, D. J.; CLOSS, D. J. Logística Empresarial: o processo de Integração da Cadeia de Suprimentos. São Paulo: Atlas, 2001.

BRUCE, M.; DALY, L.; TOWERS, N. Lean or agile A solution for supply chain management in the textiles and clothing industry? International Journal of Operations
\& Production Management, v. 24, n. 2, p. 151-170, 2004.

BUTLER, C. et al. Revamping the value chain in exhibition facilities: the case of the Dubai exhibition industry. Facilities, v. 25, n. 11/12, p. 419-436, 2007.

CARR, A. S.; KAYNAK, H. Communication methods, information sharing, supplier development and performance: an empirical study of their relationships. International Journal of Operations \& Production Management, v. 27, n. 4, p. 346-370, 2007.

CAVINATO, J. L. A general methodology for determining a fit between supply chain logistics and five stages of strategic management. International Journal of Physical Distribution \& Logistics Management, v. 29, n. 3, p. 162-181, 1999.

CHOPRA, S.; MEINDL, P. Gerenciamento da Cadeia de Suprimentos: estratégia, planejamento e operação. São Paulo: Prentice Hall, 2003.

CHOY, K. L. et al. Development of performance measurement system in managing supplier relationship for maintenance logistics providers. Benchmarking: An International Journal, v. 14, n. 3, p. 352-368, 2007.

CHRISTOPHER, M. Logística e Gerenciamento da Cadeia de Suprimentos: estratégias para a redução de custos e melhoria dos serviços. São Paulo: Pioneira, 1997.

CHRISTOPHER, M. Logística e Gerenciamento da Cadeia de Suprimentos: criando redes que agregam valor. São Paulo: Thomson Pioneira, 2007.

CHRISTOPHER, M. Supply chain migration from lean and functional to agile and customized. Supply Chain Management: An International Journal, v. 5, n. 4, p. 206-213, 2000.

COOPER, M. C.; GARDNER, J. T. Building good business relationships: More than just partnering or strategic alliances. International Journal of Physical Distribution \& Logistics Management, v. 23, n. 6, p. 14-26, 1993.

COOPER, M. C.; LAMBERT, D. M.; PAGH, J. D. Supply chain management: more than a new name for logistics. The Internacional Journal of Logistics Management, v. 8, n. 1, p. 1-14, 1997.

CORONADO, O. Logística Integrada. São Paulo: Atlas, 2007.

CORRÊA, H. L.; GIANESI, I. G. N.; CAON, M. Planejamento, Programação e Controle da Produção. São Paulo: Atlas, 2007.

COUNCIL OF SUPPLY CHAIN MANAGEMENT PROFESSIONALS - CSCMP. Conceito SCM. Lombard, 2005. Disponível em: <http://www.csmp.org/Website/ AboutCSCMP/Definitions/Definitions.asp>. Acesso em: 25 mar. 2007.

CROXTON, K. L. et al. The supply chain processes. The International Journal of Logistics Management, v. 12, n. 3, p. 13-36, 2001.

DONK, D. P V.; AKKERMAN, R.; VAART, T. V. D. Opportunities and realities of supply chain integration: the case of food manufacturers. British Food Journal, v. 110 , n. 2, p. 218-235, 2008.

DREYER, D. E. Performance measurement: a practitioner's perspective. Supply Chain Management Review, v. 4, n. 4, p. 63-68, 2000. 
FIGUEIREDO, K. F. Gestão da Capacidade e da Demanda em Serviços Logísticos. Revista Tecnologística, v. 5, n. 66, p. 46-50, 2001.

FIGUEIREDO, K. F.; FLEURY, P. F.; WANKE, P. Logística e Gerenciamento da Cadeia de Suprimentos. São Paulo: Atlas, 2006.

FISHER, C. H. What is the right supply chain for product? Harvard Business Review, v. 2, n. 75, p. 105-16, 1997.

FORSLUND, H. The impact of performance management on customers' expected logistics performance. International Journal of Operations \& Production Management, v. 27, n. 8, p. 901-918, 2007.

GIL, A. C. Como elaborar projetos de pesquisa. São Paulo: Atlas, 2006.

HOLMBERG, S. A systems perspective on supply chain measurements. International Journal of Physical Distribution \& Logistics Management, v. 30, n. 10, p. 847-868, 2000.

HUANG, S. H.; UPPAL, M.; SHI, J. A product driven approach to manufacturing supply chain selection. Supply Chain Management: An International Journal, v. 7, n. 4, p. 189-199, 2002.

KAPLAN, R. S.; NORTON, D. P. A estratégia em ação: balanced scorecard. Rio de Janeiro: Campus, 1997. $334 \mathrm{p}$.

KIRCHMER, M. E-business process networks: successful value chains through standards. Journal of Enterprise Information Management, v. 17, n. 1, p. 20-30, 2004.

$\mathrm{KOH}, \mathrm{C}$. E.; NAM, K. Business use of the internet: A longitudinal study from a value chain perspective. Industrial Management \& Data Systems, v. 105, n. 1, p. 82-95, 2005.

$\mathrm{KOH}, \mathrm{S}$. C. L. et al. The impact of supply chain management practices on performance of SMEs. Industrial Management \& Data Systems, v. 107, n. 1, p. 103-124, 2007.

LA LONDE, B. J.; MASTERS, J. M. Emerging logistics strategies: blueprints for the next century. International Journal of Physical Distribution \& Logistics Management, v. 24, n. 7, p. 35-47, 1994.

LA LONDE, B. J.; POWERS, R. F. Disintegration and Re-integration: Logistics of the Twenty-First Century. The International Journal of Logistics Management, v. 4, n. 2, p. 1-12, 1993.

LAMBERT, D. M.; COOPER, M. C.; PAGH, J. D. Supply chain management: implementation issues and research opportunities. The international Journal of Logistics Management, v. 9, n. 2, p. 1-19, 1998.

LAMBERT, D. M.; EMMELHAINZ, M. A; GARDNER, J. T. Developing and implementing supply chain partnership. The international Journal of Logistics management, v. 7, n. 2, p. 1-17, 1996.

LAMBERT, D. M.; POHLEN, T. L. Supply Chain Metrics. The International Journal of Logistics Management, v. 12, n. 1, p. 1-19, 2001.

LARSON, K. The role of service level agreements in IT service delivery. Information Management \& Computer Security, v. 6, n. 3, p. 128-132, 1998.
LEE, C. W.; KWON, I. G.; SEVERANCE, D. Relationship between supply chain performance and degree of linkage among supplier, internal integration, and customer. Supply Chain Management: An International Journal, v. 12, n. 6, p. 444-452, 2007.

LUCHI, R.; PALADINO, M. Improving competitiveness in a manufacturing value chain: issues dealing with the automobile sector in Argentina and Mercosul. Industrial Management \& Data Systems, v. 100, n. 8, p. 349-358, 2000.

MAHESHWARI, B.; KUMAR, V.; KUMAR, U. Optimizing success in supply chain partnerships. Journal of Enterprise Information Management, v. 19, n. 3, p. 277-291, 2006.

McCORMACK, K.; KASPER, K. The extended supply chain: a statistical study. Benchmarking: An international Journal, v. 9, n. 2, p. 133-145, 2002.

McIVOR, R. Outsourcing: insights from the telecommunications industry. Supply Chain Management: An International Journal, v. 8, n. 4, p. 380-394, 2003.

MENTZER, J. T. et al. Defining supply chain management. Journal of Business Logistics, v. 22, n. 2, p. 1-25, 2001.

MOBERG, C. R. et al. Do the management components of Supply Chain Management affect Logistics performance? The International Journal of Logistics Management, v. 15 , n. 2, p. 15-30, 2004

MORGAN, C. Structure, speed and salience: performance measurement in the supply chain. Business Process Management Journal, v. 10, n. 5, p. 522-536, 2004.

MORGAN, C. Supply network performance measurement: future challenges? The International Journal of Logistics Management, v. 18, n. 2, p. 255-273, 2007.

NAYLOR, J. B.; NAIM, M. M.; BERRY, D. Leagility: Integrating the lean and agile manufacturing paradigms in the total supply chain. International Journal of Production Economics, v. 62, p. 107-118, 1999.

NOVAES, A. G. Logística e gerenciamento da cadeia de distribuição: estratégia, operação e avaliação. Rio de Janeiro: Campus, 2004. 409 p.

PIRES, S. R. I. et al. Modelo de análise de cadeias de suprimentos: fundamentos e aplicação às cadeias de cilindros de GNV. Gestão \& Produção, v. 11, n. 3, p. 299-311, 2004.

PIRES, S. R. I. Gestão da Cadeia de Suprimentos. São Paulo: Atlas, 2004.

PORTER, M. E. Vantagem competitiva: criando e sustentando um desempenho superior. Rio de Janeiro: Campus, 1989.

RAINBIRD, M. Framework for operations management: the value chain. International Journal of Physical Distribution \& Logistics Management, v. 34, n. 3, p. 337-345, 2004.

REY, M. F. Indicadores de desempenho logístico. Revista Logmam, v. 30, n. 10, p. 88-90, 1998.

SAMARANAYAKE, P. A conceptual framework for supply chain management: a structural Integration. Supply Chain Management: An International Journal, v. 10, n. 1, p. 47-59, 2005. 
SILVA, E. L.; MENEZES, E. M. Metodologia da pesquisa e elaboração de dissertação. Florianópolis: UFSC/ PPGEP/LED, 2001. 121 p.

SKIPPER, J. B. et al. Towards a theoretical foundation of supply network interdependence and technology-enabled coordination strategies. International Journal of Physical Distribution \& Logistics Management, v. 38, n. 1, p. 39-56, 2008.

SPEKMAN, R. E.; KAMAUFF Jr., J. W.; MYHR, N. An empirical investigation into supply chain management. A perspective on partnerships International Journal of Physical Distribution \& Logistics Management, v. 28, n. 8, p. 630-650, 1998.

STANK, T. P. et al. Supply Chain Integration Tales From The Trenches. Supply Chain Management Review, v. 5, n. 3, p. 62-69, 2001.

STEWART, G. Supply-chain operations reference model (SCOR): the first cross-industry framework for integrated supply-chain management. Logistics Information Management, v. 10, n. 2, p. 62-67, 1997.

SUPPLY CHAIN COUNCIL. Supply-chain operations reference: model. Versão 8.0. Pittsburgh: SCC, 2002. Disponível em: <http://www.supply-chain.org.> Acesso em: 20 abr. 2007.

TAYLOR, D. H. Value chain analysis: an approach to supply chain improvement in agri-food chains. International Journal of Physical Distribution \& Logistics Management, v. 35, n. 10, p. 744-761, 2005.

THAKKAR, J.; KANDA, A.; DESHMUKH, S. G. Evaluation of buyer-supplier relationships using an integrated mathematical approach of interpretive structural modeling (ism) and graph theoretic matrix the case study of Indian automotive SMES. Journal of Manufacturing Technology Management, v. 19, n. 1, p. 92-124, 2008.

TÖYLI, J. et al. Logistics and financial performance: An analysis of 424 Finnish small and medium-sized enterprises. International Journal of Physical Distribution \& Logistics Management, v. 38, n. 1, p. 57-80, 2008.

TUBINO, M. Planejamento e Controle da Produção. São Paulo: Atlas, 2007.

van HOEK, R.; HARRISON, A.; CHRISTOPHER, M. Measuring agile capabilities in the supply chain. International Journal of Operations \& Production Management, v. 21, n. 1-2, p. 126-147, 2001.

VOLLMANN, T.; CORDON, C.; RAABE, H. Supply chain management: making the virtual organization work. Lausanne: International Institute for Management Development - IMD, 1996. (Executive Report, n. 19). WHIPPLE, J. S.; GENTRY, J. J. A network comparison of alliance motives and achievements. Journal of Business \& Industrial Marketing, v. 15, n. 5, p. 301-322, 2000. WOOD, Jr., T. Mudança organizacional. São Paulo: Atlas, 2004.

ZOKAEI, A. K.; SIMONS, D. W. Value chain analysis in consumer focus improvement: a case study of the UK red meat industry. The International Journal of Logistics Management, v. 17, n. 2, p. 141-162, 2006. 